\title{
Preparation and characterization of nanocellulose from Albizia lebbeck sawdust and their application in nanocomposites using poly(vinyl chloride) (PVC)
}

Shahin Sultana ( $\sim$ shasultana@gmail.com )

Bangladesh Council of Scientific and Industrial Research https://orcid.org/0000-0003-3671-8295

Mohammad Mahbub Reja

Dhaka College

Lutfun Naher Hilary

BCSIR: Bangladesh Council of Scientific and Industrial Research

Muhammad Saiful Islam

BCSIR: Bangladesh Council of Scientific and Industrial Research

Mohammad Zamsed Uddin

Dhaka University

Walliullah Md. Ajmotgir

Dhaka City College

\section{Research Article}

Keywords: Albizia lebbeck sawdust, PVC, cellulose, nanocellulose, nanocomposite, thermal properties, tensile properties etc.

Posted Date: April 9th, 2021

DOl: https://doi.org/10.21203/rs.3.rs-386714/v1

License: (c) (i) This work is licensed under a Creative Commons Attribution 4.0 International License.

Read Full License 


\section{Abstract}

The nanocellulose and its nanocomposites have significant importance in the most economic sectors of applications. This research involves the synthesis of nanocellulose from Albizia lebbeck wood sawdust. Quantitative evaluations of chemical components present in the sawdust of a native hardwood species Albizia lebbeck were determined by chemical analysis method. The results revealed that the approximate amount of hot water extractives, $96 \%$ ethanol extractives, alpha-cellulose, hollocellulose, hemicellulose, lignin and ash content were $6.9 \%, 7.31 \%, 40.72 \%, 65.10 \%, 24.38 \%, 25.67 \%$, and $1.10 \%$ respectively. Nanocellulose was synthesized from the extracted alpha-cellulose by acid hydrolysis method. Fouriertransform infrared spectroscopy (FTIR) characterizations have been done for Albizia lebbeck sawdust, extracted alpha-cellulose and synthesized nanocellulose respectively. The average diameter of synthesized nanocellulose was found $155.6 \mathrm{~nm}$ by particle size analyzer. Nanocellulose with different weight percentages $(2 \%, 4 \%, 6 \%, 8 \%$ and $10 \%)$ were reinforced with poly(vinyl chloride) (PVC) to prepare nanocomposites by solution casting method. The thermal stability of pure PVC, nanocellulose and $2 \mathrm{wt} \%$ nanocellulose-PVC nanocomposite was investigated and the result revealed that $2 \mathrm{wt} \%$ nanocellulose reinforced PVC nanocomposites is thermally more stable than the nanocellulose and pure PVC. The tensile properties of all nanocomposites were counducted by universal testing machine (UTM) and the highest tensile strength was obtained for $2 \mathrm{wt} \%$ nanocellulose reinforced PVC nanocomposites. The scanning electron microscope (SEM) images of $2 \mathrm{wt} \%$ nanocellulose reinforced PVC nanocomposites also exhibited the uniformly dispersion of nanocelulose in nanocomposite.

\section{Introduction}

The research on nanocellulose based nanocomposites has grown exponentially and the research subject of cellulose nanomaterials started in the mid-90s (Oksmana et al. 2016). Nanocomposites have unique properties with incorporation of very small quantities of filling materials. Nanocomposites exhibits improved stiffness, toughness, barreier properties and resistance to fire and ignition (Sheltami et al. 2015). A lot of efforts have been devoted to the development of new high performance nanocomposite films for packaging applications with polymer matrix and nanofillers that are completely renewable. Nanocellulose (NC) is made from cellulose and cellulose is the most abundant biopolymer in nature, represents a remarkable emerging class of nature-derived nanomaterial due to having biodegradibility, extraordinary mechanical properties (Dorđević et al. 2016). Almost all types of polymers, such as thermoplastic, thermosets and elastomers have been used to make new materials polymer nanocomposites which have nanosize fillers. Applications of eco-friendly, sustainable and degradable nanocomposites offer new technology and business opportunities for several sectors of the aerospace, automotive, construction, electronics, biotechnology and food packing industries. There is a tremendous interest for using bionanoparticles like nanocellulose to be applied in the new era of biocomposites (Gacitua et al. 2005, Camargo et al. 2009, Trache et al. 2020 and Chang et al. 2020). Biocomposites refers to composite materials that contain one or more naturally derived content, which can be part of the reinforcement phase or matrix phase or both in a composite system. Various bionanocomposites have 
been produced using cellulose nanocrystals (CNCs) as nanofillers and polymer matrixes from natural and renewable resources (Trache et al. 2020 and Chang et al. 2020). Joseph et al. (2020) gives a brief idea about the research and development pertaining to cellulose nanocomposites, characteristics and their biomedical applications. They reported in this review on the nanocellulose and nanocellulose based nanocomposites with natural rubber (NR), Polylactic acid (PLA), poly ethylene oxide (PEO) and polycaprolactone $(\mathrm{PCL})$ matrices. They also reported that nanocellulose is generally considered as potential and excellent reinforcing filler for manufacturing nanocomposites as they are renewable, possess lightweight and is cost effective. Naim et al. (2020) investigated and reported on the polyvinyl chloride (PVC) multiwall carbon nanotubes (MWCNTs) nanocomposite for many industrial applications such as energy storage, chemical sensors and electronics etc. Poly(vinyl chloride) (PVC) was one of the first polymers to be used in food packaging applications due to its wide acceptance for use in the preservation of foods. These materials have unique cling properties and good barrier properties for the preservation of food (Meena et al. 2017). PVC is also widely used in various biomedical applications and its thermal and mechanical properties can be enhanced by adding organic or inorganic stabilizer. PVC based nanocomposites have drawn an increasing attention to the researchers in recent years, such as $\mathrm{PVC}$ /montmorillonite (Singh et al. 2020). In this research, PVC has been used as a matrix material to make nanocomposites.

Recently, researchers have expanded attentional focus on developing nanocellulose (NC) and NC-based composites as NC is abundant, renewable, biodegradable, and ecofriendly (Lasrado et al. 2020 and Islam et al. 2014). Potential areas of application of novel nanacelluloses include reinforcing agents in nanocomposites, paper, biodegradable films, packaging products, stabilizing agents in dispersions for technical films and membranes, additives in food, texturing agents in cosmetics, and medical devices such as wound dressings and bioactive implants (Islam et al. 2014 and Kalia et al. 2011). Nanocellulose may well imparts its high stiffness and strength to improve the mechanical properties of nanocomposites (Kalia et al. 2011). Abbasi et al. (2018) reported on the preparation of $500 \mathrm{~nm}$ size nanocellulose from jute fiber waste by pulverized it into powder dispersion using ball milling technique. Hussin et al. (2020) reported on the extraction and characterization of nanocellulose from raw oil palm leaves (Elaeis guineensis) and produce 10 to $30 \mathrm{~nm}$ size nanocellulose by sulfuric acid hydrolysis at room temperature for $5 \mathrm{~h}$. Barbas et al. (2020) produce nanocellulose by the hydrolysis process from organosolv pulps of non-wood plants and the optimal conditions of process were $43 \%$ sulfuric acid, temperature $60{ }^{\circ} \mathrm{C}$, hydrolysis time $90 \mathrm{~min}$ and ultrasonic treatment 60 min respectively. Lot of articles has been found on the production of nanocelluloses, their modification and applications but limited works has been found on Albizia lebbeck wood fibers or sawdust. Nurnabi et al. (2020) investigated and reported on the chemical modification of Albizia lebbeck sawdust and their application for the sorption of $\mathrm{Pb} 2+$ and $\mathrm{Cu} 2+$ ions from aqueous solutions. Mamun et al. (2020) developed novel composite materials using Albizia lebbeck sawdust, sodium silicate solution and corn starch. They reported that the developed composites showed superior properties and have a good potential in the construction and building industries. Reports are not available in the literature regarding the synthesis of nanocellulose from Albizia lebbeck sawdust and their application to develop nanocomposite. 
In this research Albizia lebbeck sawdust were used to synthesize nanocellulose from extracted cellulose of Lebbek sawdust. Albizia lebbeck tree is known as "shirish coroi" wood. Shirish or Lebbek tree is native to Bangladesh, Southeast Asia and Australia. In this work, lebbek sawdust from the local source of Bangladesh was used as a main raw material to produce nanocellulose and nanocomposites. Sawdust is a waste product generated during processing of wood in different types of forest industries. The main objective in this research is to investigate the potential utilization of lebbek sawdust in manufacturing nanocellulose and nanocomposites.

\section{Materials And Methods}

\section{Materials}

The main raw material Albizia lebbeck sawdust was collected from Saturia Sawmill Ltd. Saturia, Manikgonj. The chemicals used in this research were acetic acid, sodium hydroxide, sulfuric acid, tetrahydrofuran (THF) and ethanol $96 \%$ etc collected from Merck, Germany. Sodium chlorite was collected from BDH, England. The matrix material used in this research was plasticized poly(vinyl chloride) (PVC) from Merck Specialities Private Limited, Mumbai, India. Distilled water was produced and collected from BCSIR Laboratories, Dhaka.

Processing of Sawdust

Sawdust was cleaned manually by removing undesirable particles and then thoroughly washed in tap water and dried in air. Cleaned sawdust was sieved by Analytical Sieve, FRITSCH analysette3, Germany. The particle sizes of mesh $60+$ sawdusts were taken for further works. The components of sawdust were analyzed by chemical methods according to Sultana et al. (2020).

Determination of hot water soluble extractives content of sawdust

The sawdust $(10 \mathrm{~g})$ was transferred into a round bottom flask and $500 \mathrm{ml}$ distilled water was added to it. The flask was set on a heating mantle for reflux $3 \mathrm{hrs}$. After finishing the refluxing, the contents of the flask filtered and dried in an oven at $105^{\circ} \mathrm{C}$ temperature. The loss of weight of sawdust was determined as hot water solubility and calculated as percentage.

Determination of $96 \%$ ethanol soluble extractives content of sawdust

Extractives content of sawdust were measured by extracting of them in $96 \%$ ethanol (100-120 ml) for 4 hours in a soxhlet apparatus. The loss of weight of sawdust was determined as extractives content and calculated as percentage.

Determination of ash content of sawdust

The ash content of sawdust was measured by using Muffle Furnace, model-CWF1200, Carbolite Ltd, United Kingdom. The samples in silica crucibles were burnt in a gas burner first to remove the fumes and 
then placed into the furnace to make ash at $575 \pm 25^{\circ} \mathrm{C}$ for 4 hours. The ash content was calculated as percentage.

Determination of acid insoluble lignin content of sawdust

Sawdust was dried after removing water extractives and $96 \%$ ethanol extractives content. Dried sawdust was taken to treat with $72 \%$ sulphuric acid hydrolysis for $2 \mathrm{hrs}$ at room temperature with constant stirring. Then the acid was diluted to $3 \%$ by adding distilled water and again refluxes for 4 hours. The filtered residue was washed and dried and calculated as percentage for acid insoluble lignin content.

Determination of hollocellulose content of sawdust

Water and ethanol extractives free sawdust were dried and taken to determine hollocellulose (cellulose + hemicelluloses) content of sawdust. It was treated with sodium chlorite solution at constant $\mathrm{pH} 4$ maintaining by adding buffer solution of sodium acetate and acetic acid. After completion of the treatment, the mixture was filtered, washed with water and dried. The white residue was calculated as percentage for hollocellulose content.

Preparation of Alpha-cellulose from hollocellulose

The hollocellulose was treated with $18 \% \mathrm{NaOH}$ solution for 3 hours at room temperature with occasional stirring. After treatment the alpha-cellulose was separated from hollocellulose as white residue. The white residue was washed and dried and calculated as percentage as alpha-cellulose.

Synthesis of nanocellulose from purified alpha-cellulose by acid hydrolysis

Purified alpha-cellulose was taken to synthesize nanocellulose. It was mixed with $64 \%$ sulfuric acid at an initial ratio of $1: 8(\mathrm{w} / \mathrm{v})$. The mixture was hydrolyzed by stirring $300 \mathrm{rpm}$ for $1 \mathrm{~h}$ at $45^{\circ} \mathrm{C}$ and then the reaction mixture was quenched by adding 10 -fold distill water. After quenching, the mixture was allowed to settle overnight in the refrigerator, and the resulting suspension was then centrifuged by Centurion Scientific Benchtop Centrifuges, Model-K241 until the $\mathrm{p}^{\mathrm{H}}$ is 6-7. The nanocellulose was separated by centrifugation and then it was sonicated by Bandelin Sonorex Digitec Sonicator, Germany for $10 \mathrm{~min}$. The product is then subjected to freeze drying to get film by removing water.

Preparation of nanocellulose-PVC nanocomposites

Numerous methods such as solvent casting, melt mixing, in situ polymerization, extrusion and layer by layer formation have been used to prepare NC-based composites (Lasrado et al. 2020). In this work, solution casting method was used to make nanocellulose-PVC nanocomposites. PVC (10 g) was dissolved in THF $(30 \mathrm{ml})$. Dried nanocellulose $(0.2 \mathrm{~g})$ was softened by adding few drops of distilled water first and then THF $(10 \mathrm{ml})$ was added into it and sonicated for 30 min separately. Solutions of PVC and nanocellulose were mixed together and stirred for 3 hours at room temperature using a magnetic stirrer. The solution was cast into a glass petridish and allowed to evaporate at room temperature for 24 hours. 
The prepared nanocomposite was then peeled off from the petridish. The nanocomposites at different loading of nanocellulose with PVC (such as $2 \mathrm{wt} \%, 4 \mathrm{wt} \%, 6 \mathrm{wt} \%, 8 \mathrm{wt} \%$ and $10 \mathrm{wt} \%$ nanocellulose with PVC content of $98 \mathrm{wt} \%, 96 \mathrm{wt} \%, 94 \mathrm{wt} \%, 92 \mathrm{wt} \%$ and $90 \mathrm{wt} \%$ respectively) were prepared by following the same procedure.

Characterization

Fourier Transform Infrared Spectroscopy (FTIR) analyses

The FTIR spectra of the cellulose, nanocellulose and nanocomposites were recorded on a Perkin ElmerFTIR/NIR, Model-Forntier Spectrophotometer. The FTIR spectra of all samples were obtained in the printed form and presented in the result and discussion section.

Size analysis

The particle size of nanocellulose was measured by dynamic light scattering using a Particle size \& Zeta Potential Analyzer (NANO-ZS, Malvern, UK) and the result was obtained as printed form and presented in the result and discussion section.

Tensile properties analyses

The tensile properties of the nanocomposites were carried out in an Universal Testing Machine (UTM), model: $1410-$ Titan $^{5}$, Load cell: $5000 \mathrm{~N}$, made in U.K. at a cross head speed of $30 \mathrm{~mm} / \mathrm{min}$. Tensile tests were conducted following ASTM D 882-02 and each test was performed until tensile failure occurred. Rectangular-shaped PVC nanocomposites film was used as test specimen. The testing values of five identical specimens were taken to calculate the average value of tensile properties.

Thermal properties analyses

The thermal properties of nanocellulose and $2 \mathrm{wt} \%$ nanocellulose loaded nanocellulose-PVC nanocomposite were measured by Simultaneous Thermal Analyzer (STA), Model No F3 Jupiter, serial no STA 449 F-3A-1311-M, NETZSCH, Germany. About 5 10 mg samples were heated in an alumina crucible from 30 to $600^{\circ} \mathrm{C}$ with a heating rate of $10^{\circ} \mathrm{C} / \mathrm{min}$ under a nitrogen atmosphere. TGA and DSC curves obtained for nanocellulose and $2 \mathrm{wt} \%$ nanocellulose-PVC nanocomposite. The weight change was recorded as a function of the heating temperature. The thermal property of pure PVC was measured by TG-GC-MS, Pyris-Clarus 680- Clsrus SQ8, Perkin Elmer, USA. Thermogravimetric ananlysis (TGA) for pure $\mathrm{PVC}$ was done with a heating rate of $15^{\circ} \mathrm{C} / \mathrm{min}$ under nitrogen atmosphere. TGA curve obtained for pure PVC heated from $40^{\circ} \mathrm{C}$ to $750^{\circ} \mathrm{C}$.

Scanning Electron Microscopy (SEM) analyses

The surface morphology of nanocellulose film and tensile fractured surface of $2 \mathrm{wt} \%$ loaded nanocellulose-PVC nanocomposites were investigated by a scanning electron microscope (JEOL JSM- 
6490LA, JEOL Ltd., Japan). The solid samples of nanocellulose film and nanocomposites were coated with ultrathin film of gold with a sputter coater. The SEM images were taken with 1000X magnification with low voltage $5.0 \mathrm{kV}$. The SEM images of nanocellulose and nanocomposite were presented in the results and discussion section.

\section{Results And Discussion}

Chemical composition of Albizia lebbeck wood sawdust

Chemical composition of Albizia lebbeck wood sawdust was analyzed and presented in the table 1. The chemical composition of different types of woods varies from species to species. Pawlicka et al. (2011) was investigated and presented the chemical composition of selected species of exotic wood derived from the region of Africa and the results are not identical but almost similar observation with this research. Almost similar lignin, holocellulose and alpha-cellulose content in eucalyptus (Eucalyptus camaldulensis) wood was also examined and reported by Gonultas et al. (2018).

Table 1 Chemical composition of hardwood Albizia lebbeck sawdust

\begin{tabular}{|ll|}
\hline Name of composition & Values as percentage (\%) \\
\hline Hot water soluble extractives & 6.9 \\
\hline Ethanol 95\% soluble extractives & 7.31 \\
\hline Lignin & 25.67 \\
\hline Hollocellulose & 65.10 \\
\hline Hemicellulose & 24.38 \\
\hline Alpha-cellulose & 40.72 \\
\hline Ash & 1.10 \\
\hline
\end{tabular}

FTIR spectroscopic analyses of sawdust and alpha-cellulose

The FTIR spectra of Albizia lebbeck sawdust, extracted alpha-cellulose and prepared nanocellulose are presented in the fig. 1. The spectral data analyses of Albizia lebbeck sawdust and alpha-cellulose are also presented in the table 2. Almost similar spectroscopic analysis was reported for eucalyptus (Eucalyptus camaldulensis) wood (Gonultas et al. 2018). The spectrum of alpha-cellulose is closure to the spectrum of cellulose microfibers extracted from Retama raetam stems (Khenblouche et al. 2019). The spectrum of alpha-cellulose (fig. 1, middle part) shows the evidence of the absence of lignin and hemicelluloses which are present in sawdust (fig.1, upper part). The characteristic cellulosic bond (-OH, C$\mathrm{H}, \mathrm{CH}_{2}, \mathrm{C}-\mathrm{C}, \mathrm{C}-\mathrm{O}$ in table 2) are present in the FTIR spectrum of isolated alpha-cellulose. 
Table 2 FTIR spectral data analyses of Albizia lebbeck sawdust, alpha-cellulose extracted from Albizia lebbeck sawdust and nanocellulose from Albizia lebbeck sawdust

\begin{tabular}{|ll|}
\hline Position $/ \mathrm{cm}^{-1}$ & Assignment \\
\hline$\sim 3339.76-3446.50$ & $\mathrm{v}(\mathrm{OH})$ broad, strong band from the cellulose \\
\hline$\sim 2923.17$ & $\mathrm{v}(\mathrm{C}-\mathrm{H})$ asymmetrical stretching \\
\hline$\sim 2901.94-2906.21$ & $\mathrm{v}(\mathrm{C}-\mathrm{H})$ symmetrical stretching \\
\hline$\sim 1735.35$ & $\mathrm{v}(\mathrm{C}=\mathrm{O})$ from the lignin and hemicelluloses \\
\hline$\sim 1593.29-1639.08$ & $\delta(\mathrm{OH})$ of the absorbed water \\
\hline$\sim 1502.96$ & $\mathrm{v}(\mathrm{C}=\mathrm{C})$ aromatic skeletal ring stretching due to lignin \\
\hline$\sim 1459.08$ & $\delta(\mathrm{C}-\mathrm{H})$ bend, alkanes \\
\hline$\sim 1377.8-1430.05$ & $\delta(\mathrm{CH})$ symmetric bending \\
\hline$\sim 1316.1-1384.27$ & $\delta(\mathrm{C}-\mathrm{H})$ plane bending \\
\hline$\sim 1234.32$ & $\delta(\mathrm{C}-\mathrm{OH}) ; \delta(\mathrm{C}-\mathrm{CH})$ \\
\hline$\sim 1158.95-1163.83$ & $\mathrm{v}(\mathrm{C}-\mathrm{C})$ ring breathing, asymmetric \\
\hline$\sim 1061.41-1112.90$ & $\mathrm{v}(\mathrm{C}-\mathrm{OH}) 2^{\circ}$ alcohol \\
\hline$\sim 933.91-1060.11$ & $\mathrm{v}(\mathrm{C}-\mathrm{OH}) 1^{\circ}$ alcohol \\
\hline$\sim 895.65-1033.98$ & $\delta(\mathrm{OH})$ out of plane bending \\
\hline
\end{tabular}

Synthesis of nanocellulose from Albizia lebbeck sawdust

Nanocellulose was synthesized from extracted alpha-cellulose of Albizia lebbeck sawdust by acid hydrolysis process. The selected conditions of acid hydrolysis are $64 \%$ sulfuric acid, $45^{\circ} \mathrm{C}$ and one hour respectively. Various methods are used to synthesize nanocellulose, such as acid hydrolysis using concentrated mineral acids to break down cellulose, ultrasonic technique by application of sound energy to physical and chemical systems to break down cellulose, and enzymatic hydrolysis using enzymes to break down cellulose etc but the acid hydrolysis method is easy and fast to produce nanocellulose that exhibit better properties (Wulandari et al. 2016 and Hu et al. 2017). FTIR spectrum and spectral data of nanocellulose are presented in fig. 1 (lower part) and table 2 respectively. Most of the peak positions of nanocellulose are not identical but closure to the peak positions of alpha-cellulose, this is due to hydrolysis of alpha-cellulose. It is also showed in fig. 1 that there are not new bonds formed in nanocellulose during hydrolysis of alpha-cellulose. 
Nanocellulose was synthesized by acid hydrolysis method and the nanoparticle size of it was measured by particle size analyzer and presented in (fig. 2). It is observed from the figure that the average diameter of prepared nanocellulose is $155.6 \mathrm{~nm}$. The range of particle size is $24.21-955.4 \mathrm{~nm}$. Wulandari et al. (2016) synthesized nanocellulose by acid hydrolysis method from the isolated cellulose of sugarcane bagasse and obtained the average diameter of $111 \mathrm{~nm}$ by transmission electron microscope (TEM) ananlysis. Beltramino et al. (2016) reported on acid hydrolysis of cellulase-pretreated fibers of cotton linters at optimal conditions ( $25 \mathrm{~min}$ hydrolysis, $47^{\circ} \mathrm{C}, 62 \mathrm{wt} \% \mathrm{H}_{2} \mathrm{SO}_{4}$ ) to prepare nanocrystalline cellulose (NCC) which particle size was found to be around $200 \mathrm{~nm}$ by particle size analyzer.

Tensile properties of nanocellulose and nanocellulose-PVC nanocomposites:

Nanocellulose reinforced poly(vinyl chloride) (PVC) nanocomposites have been prepared with different percent of nanocellulose loading. Tensile properties of virgin PVC, nanocellulose-PVC nanocomposites have been measeured following ASTM D 882-02 standard procedure. The results of tensile properties with error bars are shown in the fig. 3-4. It is found from the figures that tensile properties of nanocellulose-PVC nanocomposites increase than 100\% PVC. It is also found from the fig. 3 that the highest tensile strength is found for nanocellulose-PVC nanocomposites with $2 \mathrm{wt} \%$ nanocellulose loading. It is observed from fig. 4 that the highest elongation at break is found at $6 \mathrm{wt} \%$ nanocellulose loaded PVC nanocomposites. The tensile strength of the nanocomposites decreased with increasing nanocellulose loading (4-10 wt\%). Similar observation was reported by Kim et al. (2018). They reported on biodegradable poly(butylene succinate) (PBS) nanocomposites reinforced with cellulose nanocrystal (CNC). They synthesized 0.1-1.0 wt\% CNC-loaded PBS nanocomposite and the highest tensile strength was found by $0.1 \mathrm{wt} \% \mathrm{CNC}$ loaded PBS nanocomposites. The tensile strength of CNC-loaded nanocomposites decreased monotonically from 65.9 to $40.9 \mathrm{MPa}$ with an increasing in the CNC loading.

Thermal properties of nanocellulose and nanocellulose-PVC nanocomposites

The thermal properties of nanocellulose and $2 \mathrm{wt} \%$ nanocellulose loaded nanocellulose-PVC nanocomposite have been investigated by simultaneous thermal analysis (STA) and the data of thermogravimetric analysis (TGA) and differential scanning calorimetry (DSC) are presented in fig. 5-6 and table 3 respectively. The TGA curve and data analysis of pure PVC are presented in fig. 5 and table 3 respectively. From the TGA curve, the onset temperature of decomposition $\left(T_{0}\right)$ and the temperature at $47.24 \%$ weight loss $\left(T_{47.24}\right)$, the temperature at maximum weight loss $\left(T_{\max }\right)$ and the temperature of residual mass are presented in table 3 . From the DSC curve the first and second physically change at differential peak temperature $\left(\mathrm{DTp}_{1}\right)$ and $\left(\mathrm{DTp}_{2}\right)$ are also presented in table 3 . Almost similar TGA curve is found for pure PVC in the literature (Bahari et al. 2017).

Table 3 TGA and DSC data of PVC, nanocellulose and nanocellulose-PVC nanocomposite 


\begin{tabular}{|c|c|c|c|c|c|c|}
\hline Sample name & $\begin{array}{l}\mathrm{T}_{\mathrm{O}}{ }^{0} \mathrm{C} \\
\text { and mass } \\
\text { change } \\
(\%)\end{array}$ & $\begin{array}{l}\mathrm{T}_{47.24}{ }^{\circ} \mathrm{C} \\
\text { and mass } \\
\text { change } \\
(\%)\end{array}$ & $\begin{array}{l}\mathrm{T}_{\max }{ }^{0} \mathrm{C} \\
\text { and mass } \\
\text { change } \\
(\%)\end{array}$ & $\begin{array}{l}\text { Residue } \\
\text { at }{ }^{0} \mathrm{C}\end{array}$ & $\mathrm{DTp}_{1}$ at ${ }^{\circ} \mathrm{C}$ & $\mathrm{DTp}_{2}$ at ${ }^{\circ} \mathrm{C}$ \\
\hline Nanocellulose & $\begin{array}{l}132.9^{\circ} \mathrm{C} \\
\text { and } \\
10.73 \%\end{array}$ & $\begin{array}{l}256.5^{\circ} \mathrm{C} \\
\text { and } 36.51 \\
\%\end{array}$ & $\begin{array}{l}640{ }^{0} \mathrm{C} \\
\text { and } 76.26 \\
\%\end{array}$ & $\begin{array}{l}29.20 \% \\
\text { at } 647.3 \\
{ }^{0} \mathrm{C}\end{array}$ & $85.8^{\circ} \mathrm{C}$ & $159.6^{\circ} \mathrm{C}$ \\
\hline $\begin{array}{l}\text { 2wt\%Nanocellulose } \\
\text {-PVC } \\
\text { nanocomposite }\end{array}$ & $\begin{array}{l}210.4^{0} \mathrm{C} \\
\text { and no } \\
\text { weight } \\
\text { loss }\end{array}$ & $\begin{array}{l}310.6^{\circ} \mathrm{C} \\
\text { and } 47.24 \\
\%\end{array}$ & $\begin{array}{l}550{ }^{\circ} \mathrm{C} \\
\text { and } 87.86 \\
\%\end{array}$ & $\begin{array}{l}17.68 \% \\
\text { at } 647.3 \\
{ }^{0} \mathrm{C}\end{array}$ & $242.9^{\circ} \mathrm{C}$ & $313.6^{\circ} \mathrm{C}$ \\
\hline Pure PVC & $\begin{array}{l}55.50^{\circ} \mathrm{C} \\
\text { and } \\
0.04 \%\end{array}$ & $\begin{array}{l}340{ }^{\circ} \mathrm{C} \\
47.04 \%\end{array}$ & $\begin{array}{l}534.75^{\circ} \mathrm{C} \\
\text { and } 86.84 \\
\%\end{array}$ & $\begin{array}{l}\text { No } \\
\text { residue } \\
\text { at } 694.5 \\
{ }^{0} \mathrm{C}\end{array}$ & $\begin{array}{l}77.8^{0} \mathrm{C} \\
\text { (Bahari } \\
\text { etal.2017). }\end{array}$ & $\begin{array}{l}120.3^{0} \mathrm{C} \\
\text { (Bahari } \\
\text { etal.2017). }\end{array}$ \\
\hline
\end{tabular}

It is clear from the fig. 5-6 and table 3 that $2 \mathrm{wt} \%$ nanocellulose-PVC nanocomposite is thermally more stable than nanocellulose and pure PVC. The thermal degradation of nanocellulose is faster than the nanocellulose-PVC nanocomposite and pure PVC. The differential peak temperature of the $2 \mathrm{wt} \%$ nanocellulose-PVC nanocomposite is shifted to the higher temperature side as compared to the nanocellulose and pure PVC. Interaction of nanocellulose with PVC in the nanocomposite material enhanced its thermal properties.

Morphological Analysis by SEM

The SEM images of surface of nanocellulose film and the tensile fractured surface of $2 \mathrm{wt} \%$ nanocellulose-PVC nanocomposite were taken to investigate their morphological character. SEM images of nanocellulose and $2 \mathrm{wt} \%$ nanocellulose-PVC nanocomposite are presented in fig. 7 and 8 respectively. It is observed from the fig. 7 that the surface of nanocellulose film shows the presence of different sizes of particles on the film surface. Particle size analysis of nanocellulose was also showed the range of particle size is $24.21-955.4 \mathrm{~nm}$. Almost similar SEM image of nano film observation was reported by Hernández-Flores et al. (2020) for pure cellulose nanocrystals (CNCs) film from cotton. Uniform dispersion and distribution of nanocellulose in the PVC phase is also found in the nanocomposites (fig. 8). Nanocellulose film was dissolved in solvent and mixed with PVC solution to make nanocomposites. So nanocellulose is not found as film form in the fig. 8 but it is found as nanoform and uniformly dispersed in the PVC matrix. Strong interfacial bonding and homogenous blending between nanofiber and PVC matrix is observed in the $2 \mathrm{wt} \%$ nanocellulose-PVC nanocomposite. Lani et al. (2014) and Patel et al. (2020) were reported similar SEM images of polyvinyl alcohol (PVA)/starch nanocomposite film 
with nanocellulose from oil palm empty fruit bunch fiber and nanocomposite film of $10 \%$ polyvinyl alcohol ( $\mathrm{PVOH}) / 5 \%$ nanocellulose fiber (NCF) from agriculture waste of banana plant respectively.

\section{Conclusion}

The chemical composition analyses of Albizia lebbeck sawdust showed the presence of alpha-cellulose $40.72 \%$. Nanocellulose was successfully synthesized by acid hydrolysis method from alpha-cellulose. FTIR spectroscopic and size distribution characterization were also evaluated for synthesized nanocellulose. The particle size of the synthesized nanocellulose had an average diameter of $155.6 \mathrm{~nm}$. The acid hydrolysis method can be used for industrial production of nanocellulose due to low cost, easy and fast. So it can be concluded that Albizia lebbeck sawdust can be a suitable source for the extraction of cellulose and synthesize nanocellulose. Nanocellulose reinforced PVC nanocomposites were prepared by solution casting method with different weight percentages of nanocellulose (2-10\%). The best tensile strength obtained for nanocomposite containing $2 \mathrm{wt} \%$ nanocellulose. The SEM images confirmed the uniform dispersion of nanocellulose and strong interfacial bonding of nanocellulose into the PVC nanocomposite. Nanocomposite containing $2 \mathrm{wt} \%$ nanocellulose also exhibited increased thermal stability as compared to the nanocellulose and pure PVC. So, manufacturing of nanocellulose/ nanocomposites from waste sawdust can be profitable for commercial market in the country.

\section{Declarations}

The authors declare no conflicts of interest.

\section{Acknowledgements}

The authors would like to acknowledge the authority of Bangladesh Council of Scientific and Industrial Research (BCSIR) for providing laboratory facilities. The authors thank Md. Jaynal Abedin, Senior Scientific Officer and Zahidul Islam, Research Chemist of Fibre \& Polymer Research Division, BCSIR Laboratories Dhaka for their help to operate UTM and Particle Size Analyzer. The authors thank Samia Tabassum, Senior Scientific Officer of IFRD, BCSIR for her help to take SEM images.

\section{References}

1. Abbasi R, Baheti V (2018) Preparation of nanocellulose from jute fiber waste. J Textile Eng Fashion Technol 4(1):101-104.

2. Barbash V A, Yashchenko O V (2020) Preparation and application of nanocellulose from non-wood plants to improve the quality of paper and cardboard. Applied Nanoscience: 1-12.

3. Bahari S A, Grigsby W (2017) Andreas Krause3 Thermal stability of processed PVC/bamboo blends: effect of compounding procedures. Eur. J. Wood Prod. 75:147-159.

4. Beltramino F, Roncero M B, Torres A L, Vidal T, Valls C (2016) Optimization of sulfuric acid hydrolysis conditions for preparation of nanocrystalline cellulose from enzymatically pretreated fibers. 
Cellulose: 1-13. DOI 10.1007/s10570-016-0897-y

5. Camargo P H C, Satyanarayanan K G, Wypych F (2009) Nanocomposites: Synthesis, Structure, Properties and New Application Opportunities. Materials Research 12 (1): 1-39.

6. Chang B P, Mohanty A K, Misra M (2020) Studies on durability of sustainable biobasedcomposites: a review. RSC Adv., 10:17955-17999.

7. Đorđević N, Marinković A D, Nikolić J B, Drmanić S Z, Rančić M, Brković D V, Uskoković P S (2016) A study of the barrier properties of polyethylene coated with nanocellulose/magnetite composite film. J. Serb. Chem. Soc. 81 (0): 1-13.

8. Gacitua E W, Ballerini A A, Zhang J (2005) Polymer Nanocomposites: Synthetic And Natural Fillers A Review Maderas. Ciencia y tecnología 7(3):159-178.

9. Gonultas O, Candan Z, (2018) Chemical Characterization And Ftir Spectroscopy Of Thermally C. Maderas. Ciencia y tecnología 20(3): 431-442.

10. Hernández-Flores J A, Morales-Cepeda A B, Castro-Guerrero C F, Delgado-Arroyo F, Díaz-Guillén M R, Cruz-Soto J D L, Magallón-Cacho L, León-Silva U (2020) Morphological and Electrical Properties of Nanocellulose Compounds and Its Application on Capacitor Assembly. International Journal of Polymer Science, 2020: 1-14.

11. Hussin FNNM, Attan N, Wahab R A (2020) Extraction and Characterization of Nanocellulose from Raw Oil Palm Leaves (Elaeis guineensis). Arabian Journal for Science and Engineering 45:175-186.

12. Hu Z, Zhai R, Li J, Zhang Y, Lin J (2017) Preparation and Characterization of NanofibrillatedCellulose from Bamboo Fiber via Ultrasonication Assisted byRepulsive Effect. International Journal of Polymer Science 2017:1-9.

13. Islam M T, Alam M M (2014) Preparation of Nanocellulose: A Review. AATCC Journal of Research 1(5): 17-23.

14. Kalia S, Dufresne A, Cherian B M, Kaith B S, Averous L, Njuguna J, Nassiopoulos E (2011) CelluloseBased Bio- and Nanocomposites: A Review. International Journal of Polymer Science 2011:1-35.

15. Kim T, Jeon H, Jegal J, Kim J H, Yang H, Park J, Oh D X, Hwang S Y (2018) Trans crystallization behavior and strong reinforcement effect of cellulose nanocrystals on reinforced poly(butylene succinate) nanocomposites. RSC Adv. 8: 15389-15398.

16. Khenblouche A, Bechki D, Gouamid M, Charradi K, Segni L, Hadjadj M, Boughali S (2019) Extraction and characterization of cellulose microfibers from Retama raetam stems. Polímeros 29(1):1-8.

17. Lani N S, Ngadi N, Johari A, Jusoh M (2014) Isolation, Characterization, and Application of Nanocellulose from Oil Palm Empty Fruit Bunch Fiber as Nanocomposites. Journal of Nanomaterials, 2014: 1-9.

18. Lasrado D, Ahankari S, Kar K (2020) Nanocellulose-based polymer composites for energy applications-A review. Appl. Polym. Sci 8959:1-14.

19. Mamun C A, Arifuzzaman M, (2020) Compressive Properties of Sawdust Composites Consisting of Sodium Silicate Solution and Corn Starch as Binder. International Journal of Science and Business 4 
(1):129-136.

20. Meena P L, Vinay, Goel A, Rai V, Rao S E, Barwa M S (2017) Packaging material and need of biodegradable polymers: A review. International Journal of Applied Research 3(7): 886-896.

21. Naim A F A, AlFannakh H, Arafat S, Ibrahim S. S. (2020) Characterization of PVC/MWCNTs Nanocomposite: Solvent Blend. Sci Eng Compos Mater 27:55-64.

22. Nurnabi M, Bhowmik S, Rahman M S, Choudhury T R, Parsons A J, Young S D, (2020) Modification and Application of Albizia lebbeck Sawdust For The Sorption of Lead(II) and Copper(II) From Aqueous Solutions. Oriental Journal Of Chemistry 36 (4): 591-600.

23. Oksmana K, Aitomäkia Y, Mathewa A P, Siqueirac G, Zhou Q, Butylinaa S, Tanpichaia S, Zhoua X, Hooshmand S (2016) Review of the recent developments in cellulose nanocomposite processing. Composites: Part A 83:2-18.

24. Patel B H, Joshi P V (2020) Banana Nanocellulose Fiber/PVOH Composite Film as Soluble Packaging Material: Preparation and Characterization. Journal of Packaging Technology and Research, 1-7. https://doi.org/10.1007/s41783-020-00083-z

25. Pawlicka A, Waliszewska B (2011) Chemical Composition Of Selected Species Of Exotic Wood Derived From The Region Of Africa. Acta Sci. Pol. Silv. Colendar. Rat. Ind. Lignar 10(1): 37-41.

26. Sheltami R M, Kargarzadeh H And Abdullah I (2015) Effects of Silane Surface Treatment of Cellulose Nanocrystals on the Tensile Properties of Cellulose-Polyvinyl Chloride Nanocomposite. Sains Malaysiana 44 (6): 801-810.

27. Singh M, Somvanshi D, Singh R K, Mahanta A K, Maiti P, Misra N, Paik P (2020) Functionalized polyvinyl chloride/layered double hydroxide nanocomposites and its thermal and mechanical properties. Appl. Polym. Sci 48894:1-12.

28. Sultana T, Sultana S, Nur H P, Khan M W (2020) Studies on Mechanical, Thermal and Morphological Properties of Betel Nut Husk Nano Cellulose Reinforced Biodegradable Polymer Composites. J. Compos. Sci. 4, 83: 1-15.

29. Trache D, Tarchoun A F, Derradji M, Hamidon T S, Masruchin N, Brosse N, Hussin M H (2020)Nanocellulose: From Fundamentals to Advanced Applications. Front. Chem. 8:1-33.

30. Wulandari W T, Rochliadi A, Arcana I M (2016) Nanocellulose prepared by acid hydrolysis of isolated cellulose from sugarcane bagasse. IOP Conf. Series: Materials Science and Engineering 107:1-7.

\section{Figures}




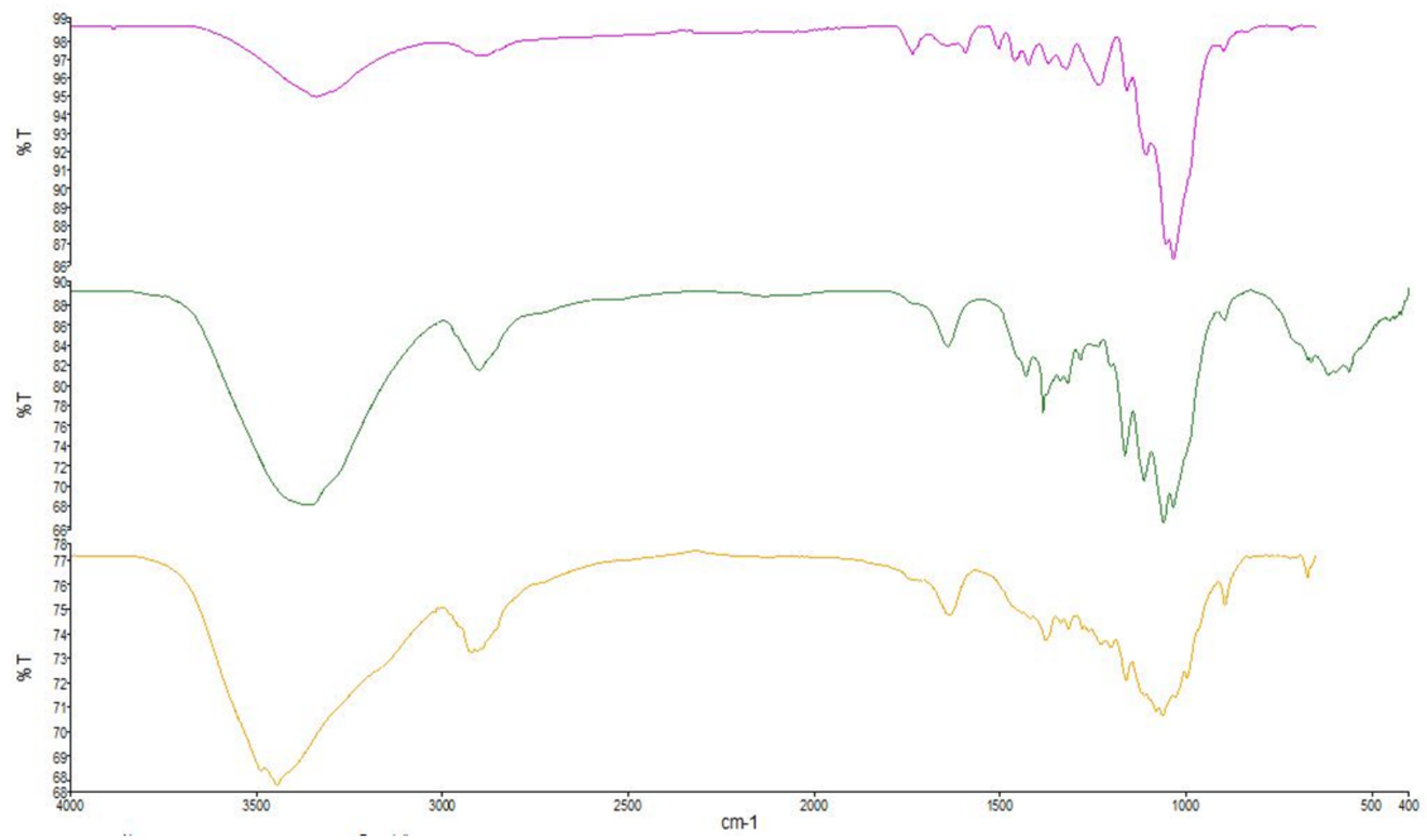

Figure 1

FTIR Spectrum of Albizia lebbeck sawdust (upper), extracted alpha-cellulose (middle) and prepared nanocellulose (lower) from Albizia lebbeck sawdust 


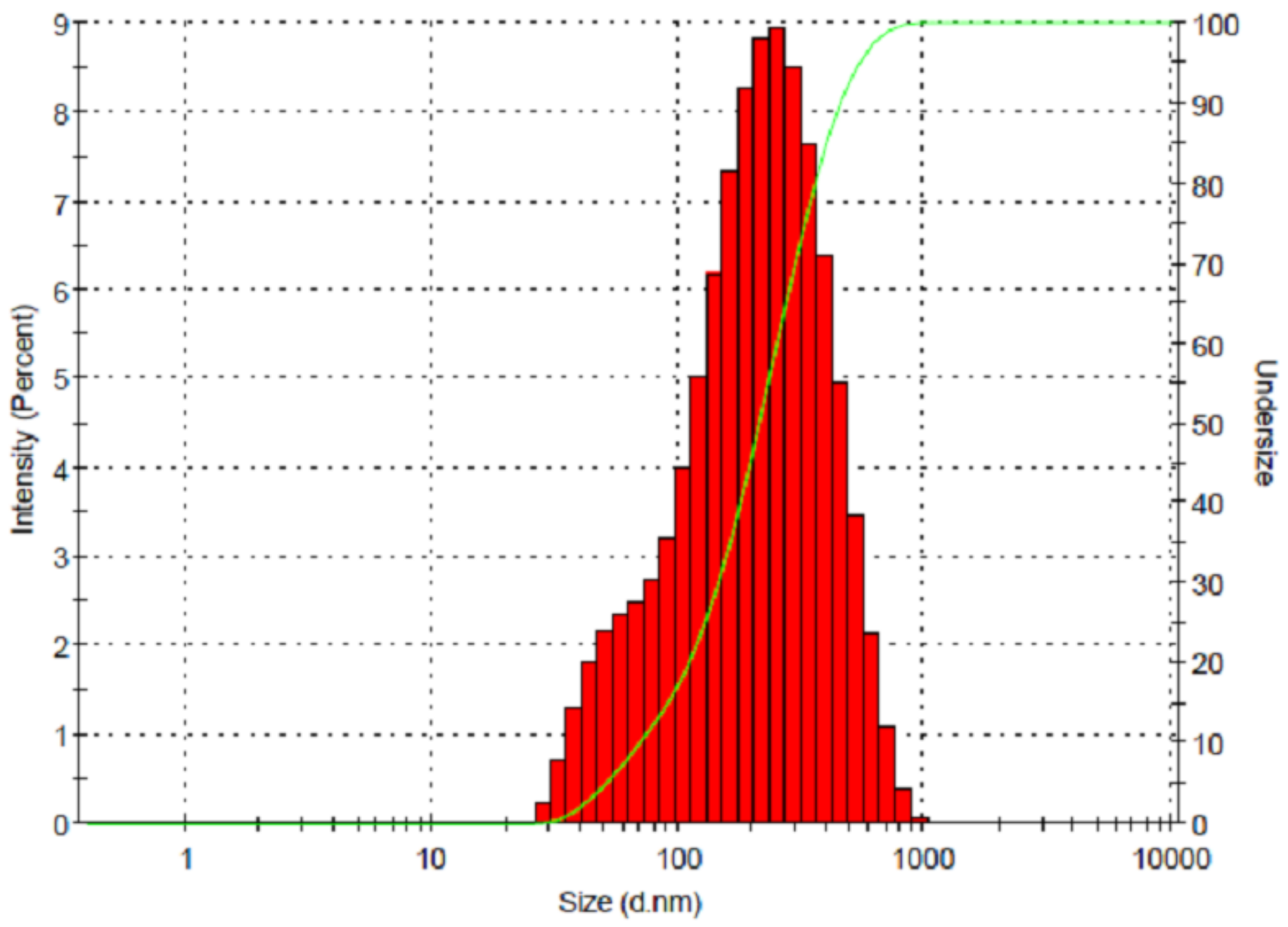

Figure 2

Particle size distribution of synthesized nanocellulose from Albizia lebbeck sawdust 


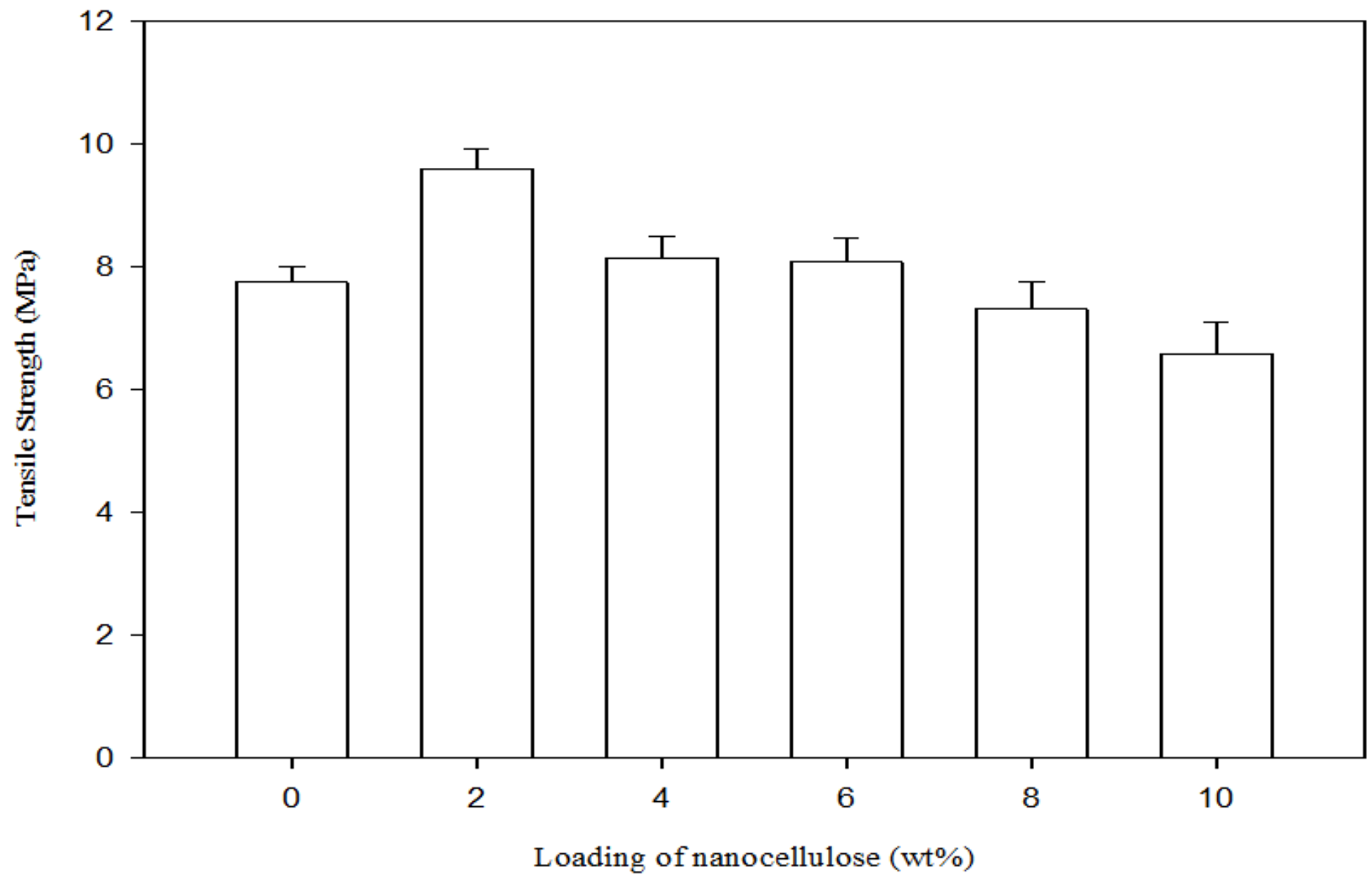

Figure 3

Tensile strength vs loading of nanocellulose (wt\%) of nanocellulose-PVC nanocomposites 


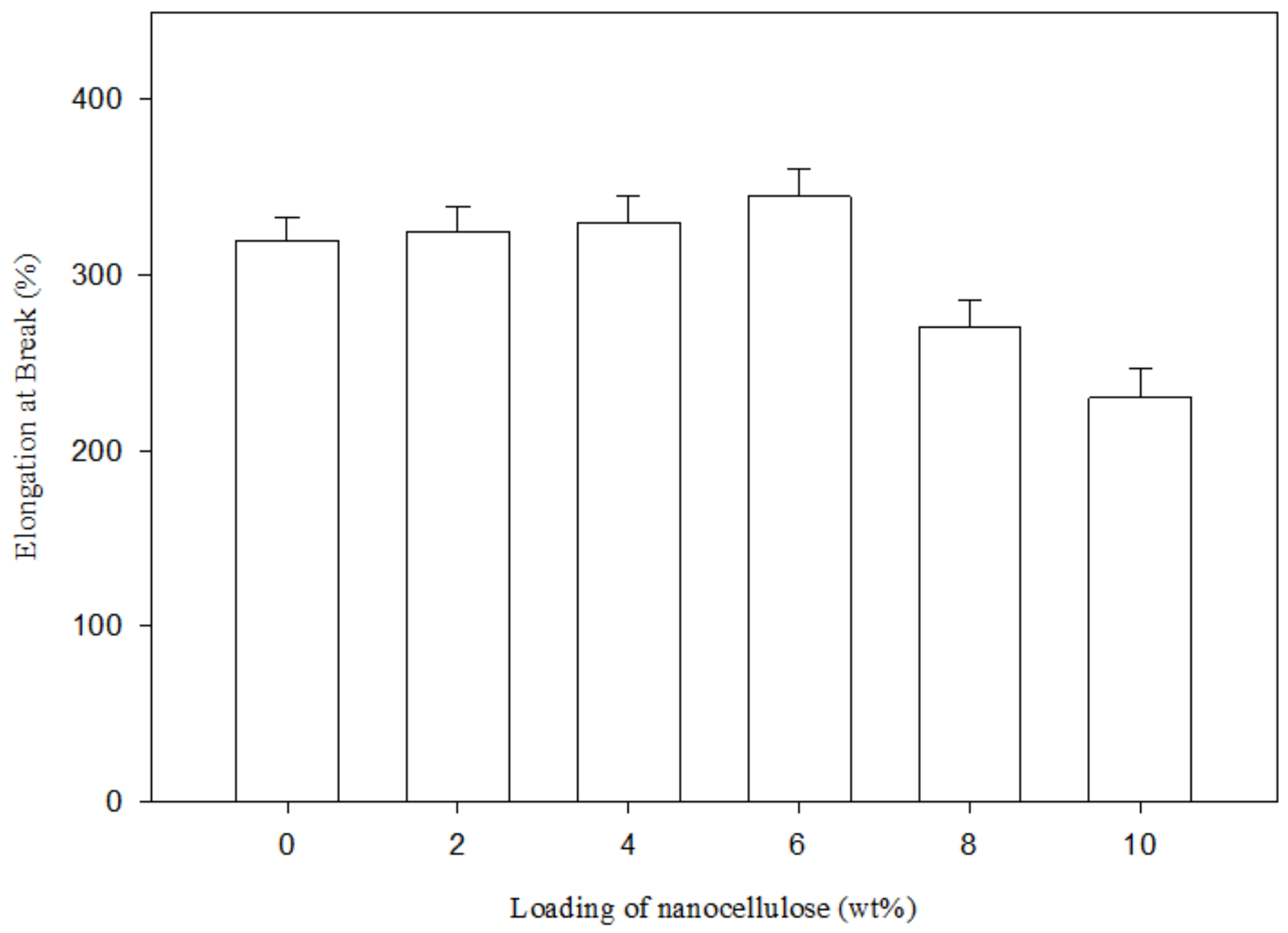

Figure 4

Elongation at Break (\%) vs loading nanocellulose (wt\%) of nanocellulose-PVC nanocomposites 


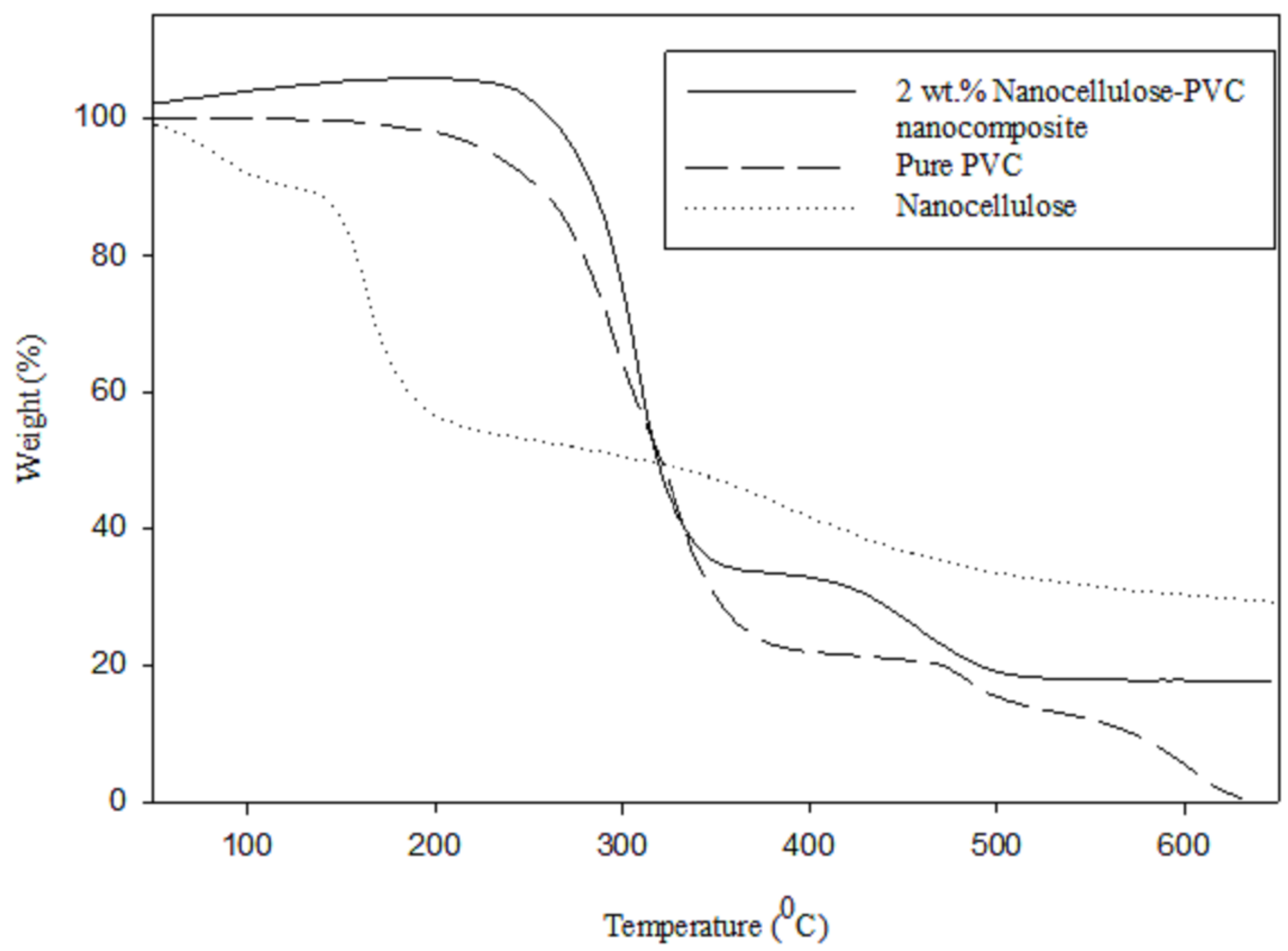

Figure 5

TGA curves of pure PVC, nanocellulose 2 (wt\%) nanocellulose-PVC nanocomposites 
$\mathrm{DSC} /(\mathrm{mW} / \mathrm{mg})$

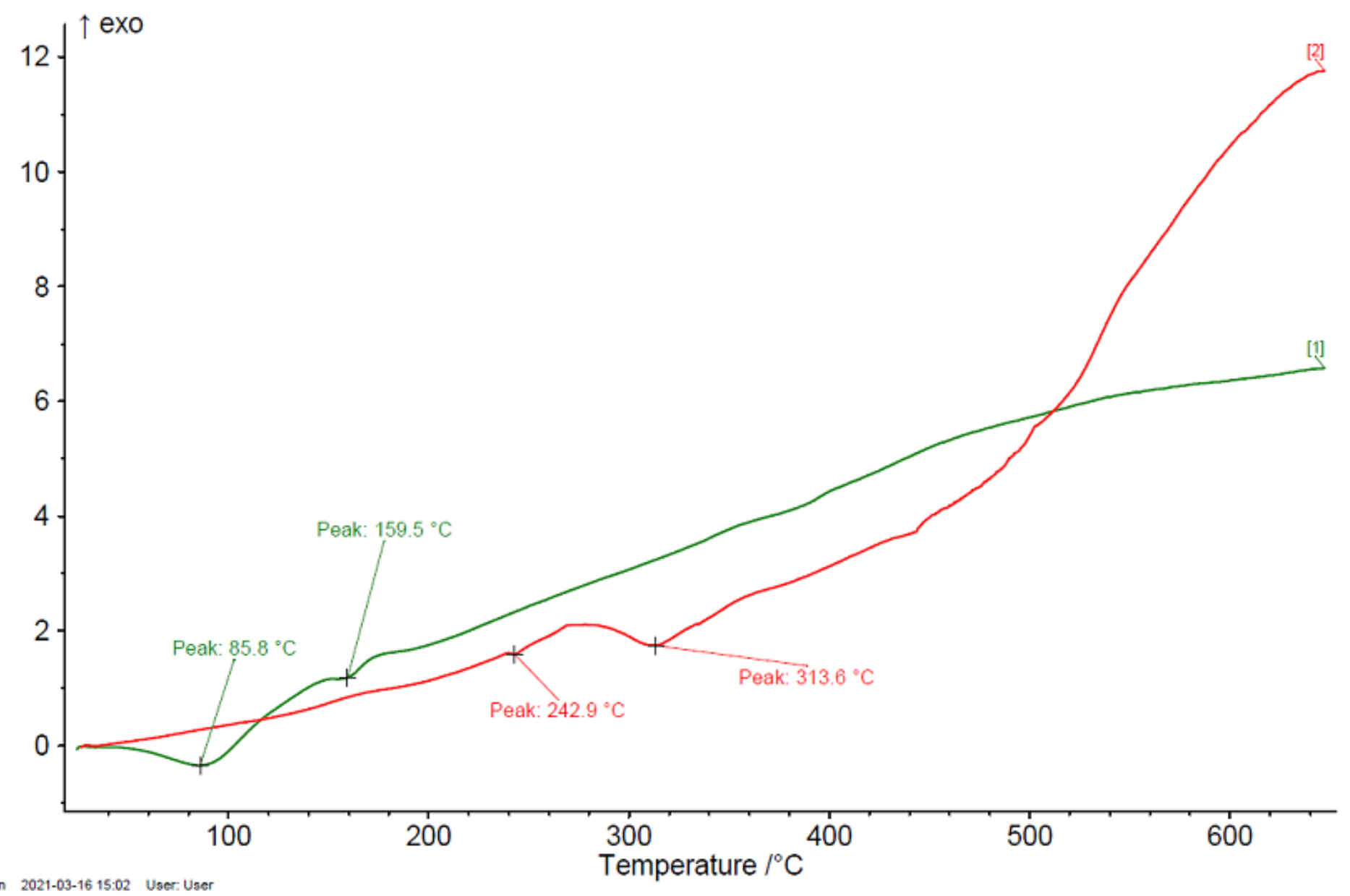

Figure 6

DSC curves of nanocellulose (1) and $2 \mathrm{wt} \%$ nanocellulose-PVC nanocomposite (2) 


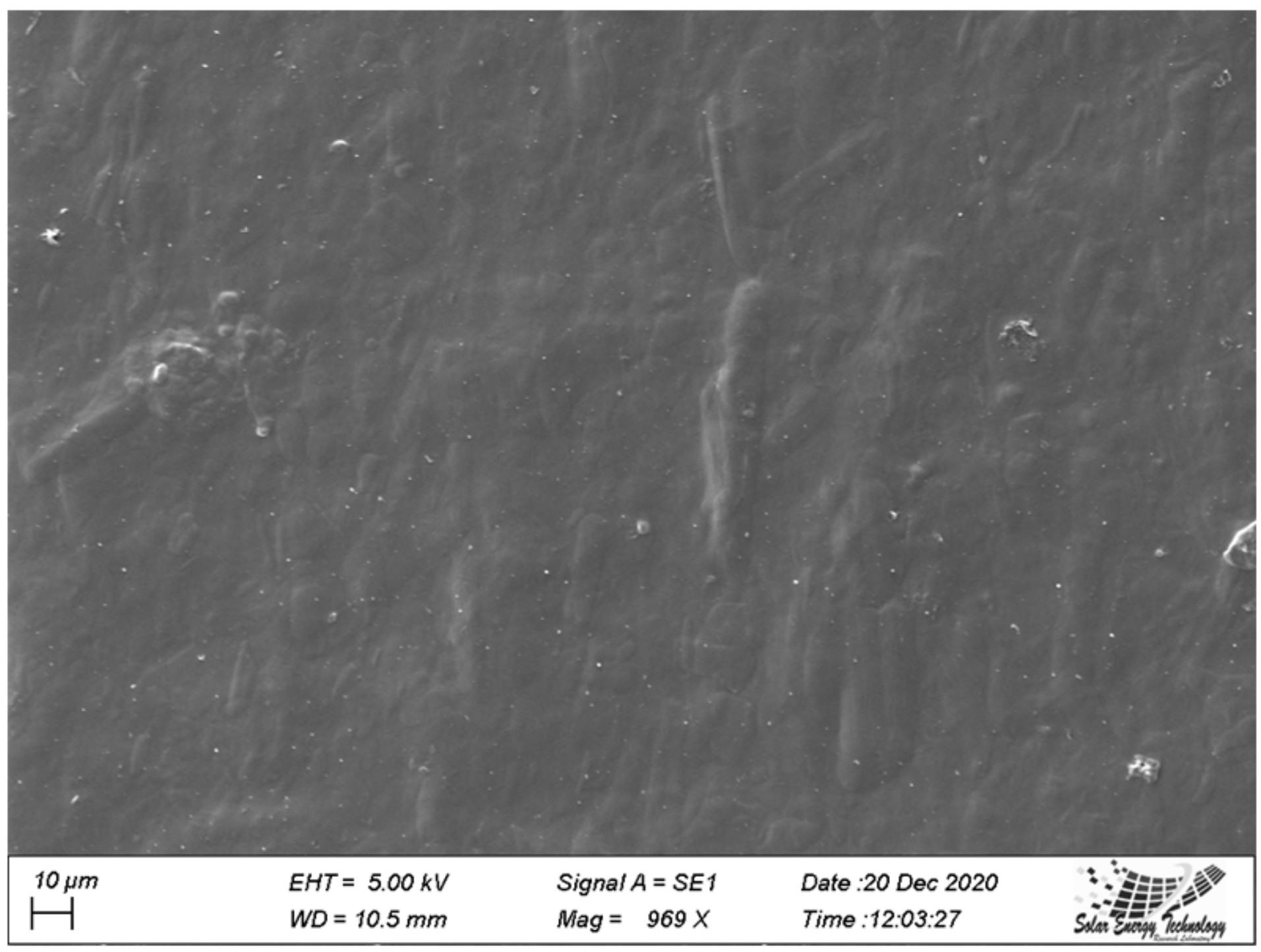

Figure 7

SEM image of nanocellulose from Albizia lebbeck sawdust 


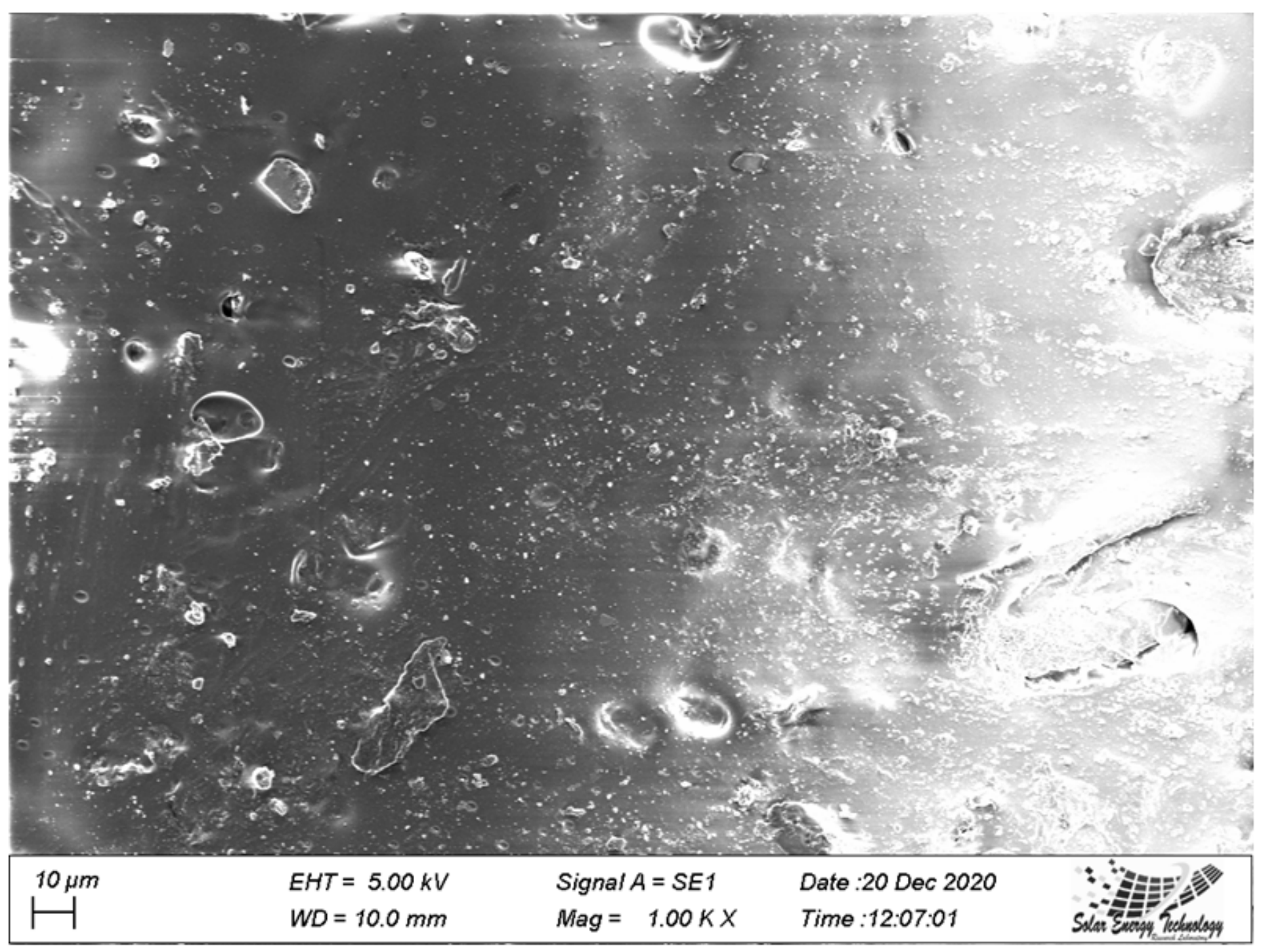

Figure 8

SEM image of of $2 \mathrm{wt} \%$ nanocellulose- PVC nanocomposite 